\title{
Concern of underdiagnosing asthma- COPD overlap syndrome if age limit of 40 years for asthma is used
}

To the Editor:

In a recent issue of the European Respiratory Journal, Sin et al. [1] presented recommendations on the definition of asthma-chronic obstructive pulmonary disease overlap syndrome (ACOS). The presented conclusions, based on a round table discussion, are very important and notable, especially considering the current lack of specific clinical criteria for ACOS. One of the key recommendations is that asthma or atopy should be diagnosed before age of 40 years (or patients should have very large airway reversibility) in order to fulfil the criteria of ACOS. However, the scientific basis of using the 40-year cut-off remains debatable. In addition, the proposal raises a major concern of underdiagnosing adult-onset asthma and ACOS if the suggested age limit is used.

ACOS has been described to develop mainly by two pathways: 1) patients with previous COPD develop asthma-like symptoms and/or asthmatic characteristics (e.g. large reversibility of the airways); or 2) patients with previous asthma continue smoking and develop nonreversible bronchial obstruction, which indicates COPD [2, 3]. The prevalence of ACOS is suggested to be $12-55 \%$ among patients with COPD and 13-61\% among patients with asthma [2]. These numbers reflect the relatively large impact of ACOS and necessitate diagnostic accuracy.

Based on cluster analyses, different phenotypes have been recognised in asthma and the age of onset has been found to be a key factor distinguishing these phenotypes [4,5]. Early-onset asthma has typically been associated with atopy and allergies, and characterised by a good response to inhaled corticosteroids and relatively high remission rate $[4,5]$. Adult-onset asthma, on the other hand, has received less attention. Recent studies have suggested adult-onset asthma to have lower remission rates $[5,6]$, more rapid loss of lung function [5] and poorer prognosis [6,7]. In a recent study of age-specific incidence of new asthma diagnoses in Finland, it was reported that most diagnoses of persistent asthma are actually made in adulthood [8]. In a US-based study, the adult-onset phenotype was reported to dominate especially among women [9]. Moreover, in a clinical cohort of consecutive, new adult-onset asthma patients (Seinäjoki Adult Asthma Study $[6,10]$ ), the mean \pm SD age of asthma onset was found to be $46 \pm 13.7$ years, which is substantially higher than the suggested limit $[6,10]$. These findings raise a question of whether the age limit of 40 years is actually applicable to real-life clinical work.

In Finland, every patient with persistent asthma is entitled to asthma reimbursement by the Social Insurance Institution of Finland (SII). The number of new asthma reimbursements reflects the number of novel asthma diagnoses made. We obtained numbers of patients from the SII and evaluated the age at which the reimbursement was obtained in Finland during 2012-2013, in order to evaluate whether diagnoses of persistent asthma were made either before or after 40 years of age. Data acquisition and calculation of novel asthma medication reimbursements were made as previously described [8].

In 2012-2013, in Finland (population 5.4 million), 26281 new patients were entitled to special reimbursement for their asthma medication (13941 females and 12340 males). Of these, only 12095 (46.0\%) persons belonged to age group 0-39 years, indicating that a majority $(54.0 \%)$ of new patients who obtained special asthma medication reimbursement were older than 40 years (figure 1). More than half $(57.9 \%)$ of females were $\geqslant 40$ years; in contrast, $50.5 \%$ of men obtained asthma reimbursement before their 40th birthday (figure 1). In conclusion, these results further suggest that most asthma is diagnosed after

@ERSpublications

The suggested asthma-onset age limit of 40 as a criterion for ACOS may lead to severe underdiagnosis of ACOS http://ow.ly/rVSk30ckrOq

Cite this article as: Tommola M, Ilmarinen P, Tuomisto LE, et al. Concern of underdiagnosing asthmaCOPD overlap syndrome if age limit of 40 years for asthma is used. Eur Respir J 2017; 50: 1700871 [https://doi.org/10.1183/13993003.00871-2017]. 


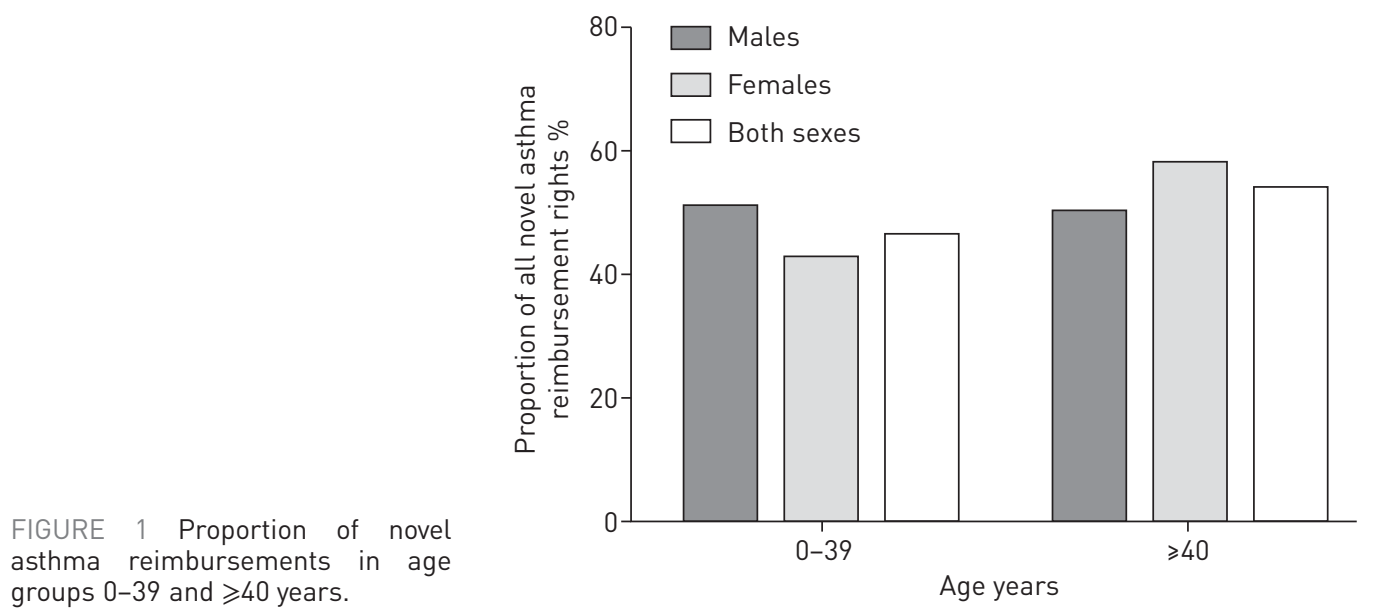

40 years of age, and thus emphasise the impact and importance of adult-onset asthma. The criterion for asthma reimbursement in Finland is variable airway obstruction demonstrated by objective lung function measurements [8]; thus, misclassified COPD does not explain the result, even though this analysis contains patients with a history of smoking.

The perception of asthma being merely a childhood-onset disease persists; however, the adult-onset phenotype of asthma has been identified in several studies and is recognised by guidelines. There is already evidence that a majority of persistent asthma may actually start in adulthood [8, 9], making it necessary to take patients with adult-onset asthma into consideration when the starting age of asthma is recommended as a diagnostic criterion. In order to obtain a diagnosis, and administer good and increasingly personalised therapy to our ACOS patients, the diagnostics must be accurate and sensitive regardless of sex, age and smoking status. Using the suggested age limit of 40 years as a criterion for ACOS may lead to severe underdiagnosis of ACOS when patients with asthma onset after 40 years of age are not included. This especially concerns women. Thus, we propose that the suggested age limit of asthma onset in the criteria of ACOS should be reconsidered.

Minna Tommola ${ }^{1}$, Pinja Ilmarinen ${ }^{1}$, Leena E. Tuomisto ${ }^{1}$ and Hannu Kankaanranta ${ }^{1,2}$

${ }^{1}$ Dept of Respiratory Medicine, Seinäjoki Central Hospital, Seinäjoki, Finland. ${ }^{2}$ University of Tampere, Faculty of Medicine and Life Sciences, Tampere, Finland.

Correspondence: Minna Tommola, Dept of Respiratory Medicine, Seinäjoki Central Hospital, FIN-60220 Seinäjoki, Finland. E-mail: minna.tommola@epshp.fi

Received: April 272017 | Accepted: April 272017

Support statement: This work was supported by the Finnish Anti-Tuberculosis Association Foundation (Helsinki, Finland), Tampere Tuberculosis Foundation (Tampere, Finland), Research Foundation of the Pulmonary Diseases (Helsinki), Jalmari and Rauha Ahokas Foundation (Helsinki), Competitive State Research Financing of the Expert Responsibility Area of Tampere University Hospital (Tampere), and Medical Research Fund of Seinäjoki Central Hospital (Seinäjoki, Finland). Funding information for this article has been deposited with the Crossref Funder Registry.

Conflict of interest: Disclosures can be found alongside this article at erj.ersjournals.com

Acknowledgements: We thank senior statistical analyser Timo Partio from the Social Insurance Institution of Finland for providing the data.

\section{References}

1 Sin DD, Miravitlles M, Mannino DM, et al. What is asthma-COPD overlap syndrome? Towards a consensus definition from a round table discussion. Eur Respir J 2016; 48: 664-673.

2 Wurst KE, Kelly-Reif K, Bushnell GA, et al. Understanding asthma-chronic obstructive pulmonary disease overlap syndrome. Respir Med 2016; 110: 1-11.

3 Barrecheguren M, Esquinas C, Miravitlles M. The asthma-chronic obstructive pulmonary disease overlap syndrome (ACOS): opportunities and challenges. Curr Opin Pulm Med 2015; 21: 74-79.

4 Wenzel SE. Asthma phenotypes: the evolution from clinical to molecular approaches. Nat Med 2012; 18: 716-725. de Nijs SB, Venekamp LN, Bel EH. Adult-onset asthma: is it really different? Eur Respir Rev 2013; 22: 44-52.

Tuomisto LE, Ilmarinen P, Niemelä O, et al. A 12-year prognosis of adult-onset asthma: Seinäjoki Adult Asthma Study. Respir Med 2016; 117: 223-229.

7 Tuomisto LE, Ilmarinen P, Kankaanranta H. Prognosis of new-onset asthma diagnosed at adult age. Respir Med 2015; 109: 944-954. 
8 Kankaanranta H, Tuomisto LE, Ilmarinen P. Age-specific incidence of new asthma diagnoses in Finland. $J$ Allergy Clin Immunol Pract 2017; 5: 189-191.

9 Sood A, Qualls C, Schuyler M, et al. Adult-onset asthma becomes the dominant phenotype among women by age 40 years. Ann Am Thorac Soc 2013; 10: 188-197.

10 Tommola M, Ilmarinen P, Tuomisto LE, et al. The effect of smoking on lung function: a clinical study of adult-onset asthma. Eur Respir J 2016; 48: 1298-1306.

Copyright @ERS 2017

From the authors:

M. Tommola and colleagues raise an important and hotly debated diagnostic criterion of asthma-chronic obstructive pulmonary disease overlap syndrome (ACOS): an age threshold of 40 years for the asthma component of ACOS. We agree with their comment that asthma can develop later in life and these patients may respond well to inhaled corticosteroids and novel biologics, similar to those with childhood-onset asthma [1]. Thus, in the roundtable consensus report [2], we suggested that the asthma component of ACOS could be fulfilled by a clinical diagnosis of asthma before age 40 years or in those without a clinical diagnosis of asthma before 40 years by demonstrating an improvement in forced expiratory volume in $1 \mathrm{~s}(\mathrm{FEV} 1)$ of $\geqslant 400 \mathrm{~mL}$ following short-acting $\beta_{2}$-agonist therapy. While a significant bronchodilatory response (BDR) is a common feature in both asthma and chronic obstructive pulmonary disease (COPD) [3], it is very unusual for COPD patients to demonstrate a BDR of $\geqslant 400 \mathrm{~mL}$ in FEV1 without a concomitant diagnosis of asthma [4]. To further improve the specificity of the asthma component of ACOS, we also suggested that in addition to all three major criteria, patients fulfil at least one of the three minor criteria: 1) a history of atopy or allergic rhinitis; 2) a BDR of $\geqslant 200 \mathrm{~mL}$ in FEV 1 on two separate visits; or 3 ) peripheral eosinophil count of $\geqslant 300$ cells per $\mu \mathrm{L}$. While none of these criteria has been validated in ACOS, we believe that these criteria are clinically workable and may be useful in identifying patients with asthma with reasonable precision. Future work will be needed to refine these criteria based on high-grade data.

@ERSpublications

While the ACOS criteria have not been validated, they are clinically workable and may identify asthma precisely http://ow.ly/qLSL30cOh4Z

Cite this article as: Sin DD, Leung JM, Wechsler ME. Concern of underdiagnosing asthma-COPD overlap syndrome if age limit of 40 years for asthma is used. Eur Respir J 2017; 50: 1701120 [https://doi. org/10.1183/13993003.01120-2017].

Don D. Sin ${ }^{1,2}$, Janice M. Leung ${ }^{1,2}$ and Michael E. Wechsler ${ }^{3}$

${ }^{1}$ Centre for Heart Lung Innovation, St Paul's Hospital, Vancouver, BC, Canada. ${ }^{2}$ Dept of Medicine (Respiratory Division), University of British Columbia, Vancouver, BC, Canada. ${ }^{3}$ Dept of Medicine, National Jewish Health, Denver, CO, USA.

Correspondence: Don D. Sin, Room 8446, 1081 Burrard Street, Vancouver, BC, V6Z 1Y6, Canada.

E-mail: Don.Sin@hli.ubc.ca

Received: June 032017 | Accepted: June 132017

Conflict of interest: Disclosures can be found alongside this article at erj.ersjournals.com

\section{References}

1 Bleecker ER, FitzGerald JM, Chanez P, et al. Efficacy and safety of benralizumab for patients with severe asthma uncontrolled with high-dosage inhaled corticosteroids and long-acting $\beta 2$-agonists (SIROCCO): a randomised, multicentre, placebo-controlled phase 3 trial. Lancet 2016; 388: 2115-2127.

2 Sin DD, Miravitlles M, Mannino DM, et al. What is asthma-COPD overlap syndrome? Towards a consensus definition from a round table discussion. Eur Respir J 2016; 48: 664-673.

3 Tan WC, Vollmer WM, Lamprecht B, et al. Worldwide patterns of bronchodilator responsiveness: results from the Burden of Obstructive Lung Disease study. Thorax 2012; 67: 718-726.

4 Tan WC, Bourbeau J, Hernandez P, et al. Bronchodilator responsiveness and reported respiratory symptoms in an adult population. PLoS One 2013; 8: e58932. 